BULLETIN Bulletin hispanique

HISPANIQUE Université Michel de Montaigne Bordeaux

118-2 | 2016

Varia

\title{
El accessus a Juan de Mena en tres comentaristas del
} Laberinto de Fortuna

anónimo del Cancionero de Barrantes, Hernán Núñez y el Brocense

Juan Casas Rigall

\section{OpenEdition}

\section{Journals}

Edición electrónica

URL: http://journals.openedition.org/bulletinhispanique/4473

DOI: 10.4000/bulletinhispanique.4473

ISSN: 1775-3821

Editor

Presses universitaires de Bordeaux

Edición impresa

Fecha de publicación: 15 diciembre 2016

Paginación: 431-452

ISBN: 979-10-300-0125-9

ISSN: 0007-4640

Referencia electrónica

Juan Casas Rigall, «El accessus a Juan de Mena en tres comentaristas del Laberinto de Fortuna »,

Bulletin hispanique [En línea], 118-2 | 2016, Publicado el 15 diciembre 2019, consultado el 30 diciembre 2019. URL : http://journals.openedition.org/bulletinhispanique/4473 ; DOI : 10.4000/

bulletinhispanique.4473 


\title{
El accessus a Juan de Mena en tres comentaristas del Laberinto de Fortuna (anónimo del Cancionero de Barrantes, Hernán Núnez y el Brocense)
}

\author{
Juan CASAs Rigall \\ Universidade de Santiago de Compostela ${ }^{1}$
}

Para Luis Iglesias Feijoo

Le Laberinto de Fortuna a été glosé, en tant que poème classique, depuis le $\mathrm{XV}^{\mathrm{e}}$ siècle. L'un de ces témoignages anonymes (MM1), un fragment du Cancionero de Barrantes, ainsi que les annotations savantes de Hernán Núñez et du Brocense, attestent l'ancienne tradition de l'accessus ou introduction à l'auteur et à son œuvre, conçue par chaque commentateur de façon particulière à partir d'un fond commun.

Mots-clés: Juan de Mena, Laberinto de Fortuna, Cancionero de Barrantes (MM1), Hernán Núñez, Francisco Sánchez de las Brozas, Accessus, Gloses.

El Laberinto de Fortuna fue glosado como poema clásico desde el s. XV. Uno de estos testimonios anónimos (MM1), fragmento desgajado del Cancionero de Barrantes, y las eruditas anotaciones de Hernán Núñez y el Brocense muestran trazas de la antigua tradición del accessus o introducción al autor y su obra, que, desde un trasfondo común, cada comentarista afronta con particularidades.

Palabras clave: Juan de Mena, Laberinto de Fortuna, Cancionero de Barrantes (MM1), Hernán Núñez, Francisco Sánchez de las Brozas, Glosas.

"Laberinto de Fortuna» has been glossed as a classic poem since the fifteenth Century. One of these anonymous evidences (MM1), a fragment from «Cancionero de Barrantes», as well as the scholarly annotations by Hernán Núnez and the Brocense, attest to an ancient tradition, the accessus or introduction to the author and his work, that each commentator treats distinctively upon a common base.

Keywords: Juan de Mena, Laberinto de Fortuna, Cancionero de Barrantes (MM1), Hernán Núñez, Francisco Sánchez de las Brozas, Glosses.

1.El presente trabajo se enmarca en la actividad de los proyectos de investigación FFI201016903 y FFI2013-42357-P, financiados por el Ministerio de Economía y Competitividad.

Bulletin Hispanique, Tome 118, nº 2 - décembre 2016 - p. 431-452. 


\section{Estudio}

El desarrollo histórico del accessus, desde la Antigüedad a la Edad Media y el Renacimiento, tiene su anclaje en las disciplinas del trivium $^{2}$.

De acuerdo con el testimonio de Diomedes, el concepto gramatical de Varrón abarcaba cuatro fases complementarias: lectio (lectura prosódica y expresivamente adecuada del texto), enarratio poetarum (comentario filológico), emendatio (notas de crítica textual) y iudicium (evaluación crítica) ${ }^{3}$. Ya en la Antigüedad, el accessus debía de ser uno de los constituyentes prologales en la enarratio poetarum, como se trasluce en los comentarios tardoantiguos de la Eneida y las Bucólicas virgilianas por Servio (ss. IV-V), de extraordinaria repercusión posterior:

In exponendis auctoribus haec consideranda sunt: poetae vita, titulus operis, qualitates carminis, scribentis intentio, numerus librorum, ordo librorum, explanatio ['Para el comentario de los autores se debe considerar esto: la vida del poeta, el título de la obra, las características formales del poema, la intención del escritor, el número de secciones del libro, el orden de las secciones y la explicación'] (Servio, Commentarius in Vergilii Aeneidos, prólogo $)^{4}$.

Al lado de esta veta gramatical, hay una raíz retórica del accessus derivada de las circumstanciae de la inventio, las siete dimensiones complementarias de la materia del discurso que se enuncian en el conocido hexámetro mnemotécnico "Quis, quid, ubi, quibus auxiliis, cur, quomodo, quando?" ["¿Quién, qué, dónde, con qué medios, por qué, cómo, cuándo?»]'. Este modelo permite estructurar el comentario en siete apartados correlativos a cada locus: persona (autor), res (obra), locus (lugar del autor y la composición), facultas (fuentes), causa (intención del autor), qualitas (cualidades formales de la obra) y tempus (época del autor y la obra).

Con gramática y retórica, el trivium se completa con la aportación de la dialéctica en el desarrollo del accessus, porque un tercer modelo comienza a perfilarse en los comentarios de Boecio (c.480-524) a obras lógicas de Aristóteles (Categorías y Sobre la interpretación) y Porfirio (Isagoge), tal vez a partir de comentarios griegos tardoantiguos. En la práctica, este esquema recoge elementos de los tipos previos (vida, título, número y orden de las partes de la

2. El término accessus se ha impuesto entre los estudiosos desde la primera mitad del siglo XX, pese a su ámbito medieval y germánico originario. Algunos de sus sinónimos documentados, históricamente más pertinentes e incluso más claros, son exordium, introitus, praefatio, proemium, prolegomena o prologus.

3. Diomedes, Ars grammatica II, en Grammatici Latini, ed. de H. Keil, Leipzig, 1857, t. I, p. 426, líneas 21-31 (reimpresión, Hildesheim, Georg Olms, 1961).

4. Servii grammatici qui fevntur in Vergilii carmina comentarii, ed. de G. Thilo y H. Hagen, Leipzig, 1881-1887, t. I, p. 1 (reimpresión, Hildesheim, Georg Olms, 1961).

5. Lo cita Mateo de Vendôme en su Ars versificatoria (s. XII). Con anterioridad, con ligeras variantes, se encontraba en el comentario de Cicerón por Victorinus (s. III) y en la retórica de Iulius Victor (s. IV). 
obra, intención autorial, materia y forma), pero incorpora la utilitas operis, que se desgaja de la intención del autor, y, en particular, añade la pars philosophiae o disciplina a que pertenece la obra.

En su aplicación práctica, en estos tres esquemas de comentario es común que se eliminen algunos constituyentes. Así, en el tipo serviano se tiende a prescindir del análisis del número y orden de las partes de la obra: pertinente para el examen de Virgilio, resulta innecesario en otros casos. La modalidad basada en las circumstanciae a menudo se ciñe a persona, lugar y tiempo. Y lo mismo cabe decir con respecto al desarrollo de raíz boeciana, que no ha sido documentado en su formulación ideal completa.

Además, un mismo comentarista puede valerse de distintas modalidades de accessus. Así, en su comento de los Disticha Catonis, Remigio de Auxerre (c. 841-908) utiliza consecutivamente tres alternativas: a) una abreviación de modelo en torno a las circumstanciae (persona, locus, tempus y causa scribendi), b) este modelo íntegro, con sus siete elementos, y c) el tipo boeciano ceńido a vida, título y pars philosophiae ${ }^{6}$.

Una interesante antología de accessus ad auctores conservada en tres manuscritos alemanes del s. XII y principios del s. XIII combina introducciones a los clásicos grecolatinos (Homero u Ovidio) con autores tardoantiguos (Prudencio o Boecio) y medievales (Pamphilus), con trazas del modelo de Servio pero marcado predominio de la evolución boeciana ${ }^{7}$.

Pese a la importancia de gramática, retórica y dialéctica en la configuración del accessus, su ámbito de aplicación pronto excedió esta esfera del trivium para alcanzar obras legales o médicas e incluso, después de las reticencias iniciales, la exégesis bíblica. Con el paso del tiempo y esta amplitud de miras, los esquemas de accessus siguieron evolucionando. En torno al siglo XII, del mismo Boecio (De differentis topicis) se toma la organización en dos estratos, al distinguirse entre ars extrinsecus, que atañe a la disciplina o el género de la obra, y el ars intrinsecus, el estudio de la obra en sí, aquí con atención a los elementos tradicionales (autor, título, intención, etc.). Y en el siglo XIII se incorpora otro modelo basado en las cuatro causas aristotélicas: causa eficiens (autor), causa materialis (materia y fuentes de la obra), causa formalis (forma) y causa finalis (intención del autor y finalidad de la obra). En adelante, si bien el sistema de las circumstanciae se consideraba anticuado ya en el siglo XI, los esquemas serviano, boeciano y aristotélico del accessus perviven hasta entrado el Renacimiento, y en el seno mismo de este trabajo tendremos ocasión de comprobarlo ${ }^{8}$.

6. Augusto Mancini, «Un commento ignoto di Remy d'Auxerre ai Disticha Catonis», Rendiconti della R. Accademia dei Lince (serie 5), no 11, 1902, p. 175-198.

7. Editado y estudiado por Robert Huygens, Accessus ad auctores. Bernard d'Utrecht. Conrad d'Hirsau, Dialogus super auctores. Édition critique, Leiden, Brill, $1970^{2}\left(1954^{1}\right)$, p. 1-6 y $18-$ 54. Una selección de estos textos en versión inglesa se incluye en A. J. Minnis, A. B. Scott y D. Wallace, Medieval Literary Theory and Criticism (c. 1100-c. 1375). The Commentary-Tradition, Oxford, Clarendon Press, 1988, p. 12-36.

8. Los trabajos que inauguran el estudio moderno del accessus son obra de Edwin A. Quain, "The Medieval Accessus ad auctores», Traditio, no 3, 1945, p. 215-264, y Richard W. Hunt, "The 
Falta un estudio histórico del accessus en las letras ibéricas desde la Edad Media al Siglo de Oro 9 . Sin embargo, someras calas en tres autores, por mínima muestra, certifican de inmediato su interés.

Por comenzar en el entorno del Laberinto, en su traducción y glosas de la Eneida (1428), Enrique de Villena demuestra la vigencia del modelo que atiende a autor, título, materia, finalidad y pars philosophiae, justificado "por quanto el deseo del entendido leedor ante de començar la ystoria cobdiçia saber quál actor la fizo e de qué nombre titulada e qué es lo que tracta e a qué fyn es fecha e a cúya parte de philosophía pertenesçe» ${ }^{10}$. En su desarrollo, trata Villena todos estos elementos, si bien la disposición estructural no respeta estrictamente la quíntuple división; en particular, la explicación del título de la obra queda implícita en las referencias a la "ystoria de Eneas». Además, a la manera del accessus tardoantiguo y medieval, algunos constituyentes se pueden desdoblar, como el «a qué fin», que combina la intentio auctoris con la utilitas operis. La cita expresa del comentario virgiliano de Servio reafirma lo obvio

Introductions to the "Artes» in the Twelfth Century», en Studia Mediaevalia in honorem admodum reverendi patris Raymundi Josephi Martin, Bruges, De Tempel, 1948, p. 85-112. El artículo de Hunt tuvo mayor repercusión por haber identificado el modelo basado en las circumstanciae y haber propuesto una esquemática tipología del accessus -entre los que principalmente nos interesan, tipo A (circunstamciae), tipo B (serviano) y tipo C (boeciano)-. Esta taxonomía fue difundida, comentada y puesta al día por dos influyentes estudios posteriores, los libros de Alastair J. Minnis, Medieval Theory of Authorship. Scholastic literary attitudes in the later Middle Ages, London, Scolar Press, 1984, p. 9-72, y Rita Copeland, Rhetoric, Hermeneutics and Translation in the Middle Ages. Academic Traditions and Vernacular Texts, Cambridge, U. P., 1991, p. 63-86. Desde otra perspectiva, que enfoca la glosa marginal en cuanto instrumento mnemotécnico, son de interés los asientos de Mary Carruthers, The Book of Memory. A Study of Memory in Medieval Culture, Cambridge, U. P., $2008^{2}$ (19901), p. 309-324. Entre las aportaciones hispanas, destaca el trabajo de César Domínguez, El concepto de materia en la teoría literaria del Medievo. Creación, interpretación y transtextualidad, Madrid, CSIC, 2004, p. 61-81, con juiciosa evaluación crítica de la bibliografía anterior. Sobre la función de la glosa en su texto con particular atención a obras legales, son asimismo sugerentes las reflexiones de Jesús D. Rodríguez Velasco, Plebeyos márgenes. Ficción, industria del derecho y ciencia literaria (siglos XIII-XIV), Salamanca, SEMYR, 2011.

9. Como punto de referencia, contamos con los panoramas sobre el prólogo por Alberto Porqueras Mayo, El prólogo en el Renacimiento español, Madrid, CSIC, 1965, y Jesús Montoya e Isabel de Riquer, El prólogo literario en la Edad Media, Madrid, UNED, 1998. Sin embargo, en ninguno de sus respectivos corpus de estudio se incluye el accessus filológico. En cambio, dedica jugosas páginas al accessus castellano del s. XV Julian Weiss, The Poet's Art. Literary Theory in Castile c. 1400-60, Oxford, The Society for the Study of Mediaeval Languages and Literature, 1990, p. 107-117, con apuntes sobre la versión de la Eneida por Enrique de Villena y la Coronación de Mena, entre otras obras vernáculas del tiempo. El mismo Weiss ha establecido un catálogo de comentarios tardomedievales castellanos, a propósito de obras romances («Vernacular Commentaries and Glosses in Late Medieval Castile, I: A Checklist of Castilian Authors», en B. Taylor, G. West y J. Whetnall, Text, Manuscript, and Print in Medieval and Modern Iberia: Studies in Honour of David Hook, New York, HSMS, 2013, p. 199-243) y traducciones de clásicos («Vernacular Commentaries and Glosses in Late Medieval Castile, II: A Checklist of Classical Texts in Translation", en J. Weiss, L. Haywood y A. Beresford, Medieval Studies in Memory of Alan Deyermond, Woodbridge, Tamesis, 2013, p. 237-271).

10. Enrique de Villena, Traducción y glosas de la Eneida, ed. de P. M. Cátedra, Salamanca, Biblioteca Española del siglo XV, 1989, t. I, p. 15-30. 
con respecto a la concepción de este accessus, si bien la atención a la "parte de philosophía» remite en concreto al desarrollo boeciano.

Villena no había declarado este mismo objetivo en los preliminares de su Exposición del salmo "Quoniam videbo» (1424) por el género diverso de la obra comentada, de materia bíblica. Con todo, en apelación a Juan Fernández de Valera, la exégesis viene antecedida de un sintético accessus, muy esquemático, pero prueba de que en los contextos proemiales del comentario el modelo usual tiende a aflorar cuando menos tímidamente, aquí a propósito del autor y la utilitas de la obra:

Plógome porque usávades la reçitaçión dél [el salmo Quoniam videbo]; e plégavos de la continuar: sentiredes por ende mayores consolaçiones spirituales e remedio en las tenporales anxiedades, mejoramiento de vuestra vida e illuminaçión de vuestro entendimiento e otros provechos, que de aquestos entender se pueden, por los grandes misterios e manifiestas virtudes que en él son, en aquellos çiento e cínqüenta salmos suyos, maguer todos non los fizo Davit, sinon los çiento, e después, a ymitaçión suya, los fijos de Coré añadieron, e por Asaf fueron cunplidos. Con todo eso, a Davit todo el Salterio titulado es, por ser por él començado e fazer la mayor parte e dar lunbre exenplar a los después continuantes.

¿Qué diré del bien deste libro? Tantos son los secretos quel Spíritu Sancto a los salmistas reveló que umano entendimiento non los podría conprehender. E de cuyas virtudes muchos an escripto, singularmente sant Gerónimo, que pone sean virtudes generales e comunes en los dichos salmos e particulares a cada uno, entre las quales cuenta que qualquier triste o tenptado, diziendo algúnt salmo, resçibe tenpramiento a su tristeza e esfuerço en la tenptaçión ${ }^{11}$.

En algunos de sus escritos, el propio Juan de Mena proporciona ejemplos análogos de notable interés. De este modo, el prólogo de su romanceamiento de la Ilias Latina (c. 1442) incluye una extensa vita de Homero, al lado de una sucinta explicación del título y de la materia de la obra-el exiguo lapso temporal de la historia correspondiente a los episodios homéricos-. Se advierten, pues, de manera palmaria elementos básicos del accessus tradicional ${ }^{12}$. Por ańadidura, las autoglosas menianas en la Coronación del Marqués de Santillana aportan una perspectiva complementaria: en el «exordio», para "poner en orden» los detalles de la introducción, Mena distingue cuatro "preámbulos», en donde trata sucesivamente el título del poema, su género - que atañe al modus dicendi, con base en una interpretación de la poética aristotélica sui generis y de prestado-, la materia y las fuentes -es decir, una cuestión de quibus auxiliis o de causa materialis- ${ }^{13}$.

11. Pedro M. Cátedra, Exégesis, ciencia, literatura. La Exposición del salmo "Quoniam videbo" de Enrique de Villena., Madrid, El Crotalón, 1985, p. 88-89. No se le ocultan a Cátedra los antedichos elementos embrionarios del accessus en el prólogo de Villena (ibid., p. 47).

12. Juan de Mena, La Ilíada de Homero, ed. de T. González Rolán, Ma F. del Barrio y A. López Fonseca, Madrid, Ediciones Clásicas, 1996, p. 104-109.

13. Juan de Mena, La Coronación, ed. de M. Kerkhof, Madrid, CSIC, 2009, p. 3-6. Su interpretación del género comedia sigue el comento dantesco de Benvenuto da Imola; véase Miguel Ángel Pérez Priego, «De Dante a Juan de Mena: sobre el género literario de "comedia"», 1616. Anuario de la Sociedad Española de Literatura General y Comparada, n 1, 1978, p. 151-158. 
En el tránsito de los siglos XV a XVI, y de la erudición cuatrocentista al Humanismo pleno, los accessus de Antonio de Nebrija se hallan en esta misma encrucijada: de una parte, se advierte el peso de la tradición; de otra, los viejos patrones se encuentran con nuevos planteamientos. Así, en su edición comentada de las Sátiras de Persio, Nebrija se acoge a los dos elementos de la introducción que considera imprescindibles: a partir del incipit del impreso, "A. Persii Flacii Satyrarvm liber vnicvs incipitvr foeliciten, afirma la necesidad de atender al autor y la materia de la obra ${ }^{14}$. A renglón seguido, en el primer dominio, Nebrija identifica al poeta entre sus homónimos, analiza su nombre y sintetiza brevemente su vida y obra; y, en la segunda esfera, trata del género de la sátira y aclara su etimología. La importancia de estas noticias se subraya en el colofón de la estampa sevillana de 1504, en donde a la ponderación del texto anotado se suma el interés de la vida del poeta y la definición de sátira («ac insuper annotationes cum eiusdem poetae vitae et satyrae expositione»). Pero más llamativo resulta que, en el folio final del último cuadernillo de este impreso, antes del epigrama laudatorio de Antonio Carrión, se incluyan dos parágrafos bajo los epígrafes «Vita Persii» y "Qvid est satyra», que reiteran y complementan la información de los preliminares: acaso por no desperdiciar blanco de página, se aprovecha para incidir en elementos esenciales del accessus ${ }^{15}$.

Este modelo reducido a vita y materia-género, ya sintético de por sí, se encuentra quintaesenciado en la edición nebrisense de Prudencio (1512): en el prólogo-dedicatoria a Diego Ramírez de Villaescusa, a Nebrija le interesa principalmente justificar la auctoritas gramatical de un poeta cristiano $\mathrm{y}$, con ello, la pertinencia de su propia tarea filológica. Aun así, no falta un constituyente esencial del viejo accessus: otra vez la vita auctoris. El antiguo patrón se desdibuja, pues, pero se resiste a desaparecer ${ }^{16}$.

Los tres comentarios al Laberinto de Fortuna que nos proponemos analizar confirman el bosquejo anterior.

En el siglo XV, los comentaristas hispanos pronto se interesaron por el Laberinto de Fortuna, poema vernáculo con una marcada impronta de erudición grecolatina, y, así, susceptible de ser explanado al modo tradicional. Además de MM1, se glosa la composición de Mena en los cancioneros PN7, BC3,

14. «Hic titulus duo quae sunt in cuiusque operis indice necessaria tangit, auctorem videlicet, et libri materiam» [«Este título atañe a dos cosas necesarias en el epígrafe de cualquier obra, es decir, el autor y la materia del libro»]. Cito por la edición de Milagros del Amo Lozano, Los comentarios de Nebrija a Persio. Edición y estudio, Tesis Doctoral, Universidad de Murcia, 1999, p. 43.

15. Antonio de Nebrija, In A. Persium Flaccum poetam satyricum interpretatio, Sevilla, Jacobo Cromberger, 1504. Una reproducción facsimilar se incluye en Del Amo Lozano, op. cit.

16. Avrelii Prudentii Clementis V. C. Libelli cum commento Antonii Nebrissensis, ed. de F. González Vega, Salamanca, Ediciones Universidad de Salamanca, 2002, p. 210-213. Sobre el comentario nebrisense y su evolución, véase Jeremy Lawrance, «Nebrija y el comentario de textos», Insula, n 551, 1992, p. 15-17, y «El comentario de textos, III: después de Nebrija», en C. Codoñer y J. A. González Iglesias, Antonio de Nebrija: Edad Media y Renacimiento, Salamanca, Ediciones Universidad de Salamanca, 1994, p. 179-193, así como Felipe González Vega, "Tradición e innovaciones en la comentarística medieval y del Renacimiento», Veleia, $\mathrm{n}^{\circ} 11,1994$, p. 299-316. 
NH5, SV2 y ML2, un conjunto textual que presenta tanto interrelaciones como diferencias derivadas de diversos estratos de anotación ${ }^{17}$. De un lado, todos estos manuscritos recogen una glosa cuatrocentista común que presenta una circunstancia de excepcional interés: según ya advirtió Street a propósito de PN7, aquel comentario primitivo se remonta siquiera parcialmente a una autoglosa de Juan de Mena, como demuestra con diafanidad este pasaje sobre la alusión a la Ilíada en el verso 978 del Laberinto $^{18}$ :

PN7 Ylíada: esta Ylíada de Omero oue tradusido o romançado para el seńor Rey, donde largamente fablé de su vida; por ende, pues que alá fablé, aquí non fago más mjnción.

BC3 Esta Ylíada de Omero ouo tradufido o arromançado para el señor Rey, donde largamjente fabla de su vida; por ende, pues allá, aquj non fago más minción.

NH5 Esta Ilíada de Omero houo tradulfido ho [...]do para el senyor Rey, adonde largamente fabla de su vida; por ende, pues allá, aquí non faguo más m[...].

SV2 Elíada: esta de Omero ouo tradufido o rromancado para el senor Rey, donde largamiente fabla de su vida; por ende, pues allá, aquj non más.

ML2 Esta Ylíada de Omero ove traduzido o rromançado para el señor Rey, donde largamente fablé de su vida; por ende, pues allá, aquí no más ${ }^{19}$.

Como Mena, en efecto, romanceó la Ilias Latina, la primera persona verbal de la glosa según PN7 y SV2 debe de corresponder al poeta cordobés. Pero, frente a estos dos testigos, obsérvese cómo en SV2 se emplea la tercera persona y, en especial, de qué modo los copistas de $\mathrm{BC} 3$ y NH5 -en este, es dudosa la forma de haber- se quedan a medio camino en la modificación, y ouo-houo tradufido y fabla conviven con fago-faguo.

Por otra parte, si estos cinco cancioneros se atienen al texto de una misma glosa -con omisiones aisladas y ligeras variantes de copista como las anteriores-, el caso de MM1 es distinto, pues, aun compartiendo esa base, presenta una redacción mucho más extensa y rica. Por añadidura, en PN7 y BC3 la glosa

17. La glosa del cancionero NH5 es difícilmente legible en la actualidad, pues, hacia 1890, en el proceso de su restauración y encuadernación, se consideró oportuno no solo guillotinar, sino incluso lavar los márgenes. Con todo, bastantes escolios, total o parcialmente, aún resultan comprensibles.

18. Florence Street, "The Text of Mena's Laberinto in the Cancionero de Ixar and Its Relationship to Some Other Fifteenth-Century Mss.», Bulletin of Hispanic Studies, no 35, 1958, p. 63-71 [69]. Señala asimismo Street cómo en el comentario de la copla 217 también aflora la primera persona, que, tras el precedente de la estrofa 123, es atribuible a Mena.

19. Cito por reproducciones digitales de estos manuscritos: PN7 (Paris, Bibliothèque Nationale de France, ms. Esp. 229), BC3 (Barcelona, Biblioteca de Catalunya, ms. 1967), NH5 (New York, Hispanic Society of America, ms. HC 397/703), ML2 (Madrid, Fundación Lázaro Galdiano, ms. 208) y SV2 (Sevilla, Biblioteca Colombina, ms. 83.6.10). Las abreviaturas se desarrollan sin marca. Puntuación, mayúsculas y separación de palabras siguen el uso moderno. En el problemático caso de $\mathrm{NH} 5$, se emplean puntos suspensivos entre corchetes para pasajes ilegibles, y el subrayado para letras inseguras. 
primitiva fue secundada por manos posteriores, probablemente en el siglo XVI, que aprovecharon los generosos márgenes del folio para añadir una anotación paralela y complementaria más acorde con los gustos humanísticos. Así, en PN7 hay dos escoliastas tardíos, uno de los cuales anota con profusión aquellos pasajes en que considera apropiado aducir a los clásicos (Virgilio, Ovidio o Lucano), mientras que un segundo glosador se limita a calcar varios párrafos del comentario de Hernán Núñez. Análogamente, en BC3 hay al menos un escoliasta tardío que, de manera muy sucinta, presenta también concordancias clásicas de los versos de Mena ${ }^{20}$.

En esta tradición cuatrocentista de comentarios, el testimonio de mayor interés para nuestro estudio es MM1, fragmento del Cancionero de Barrantes, cuya compilación se suele situar entre 1456 y $1480^{21}$. Algunas referencias históricas en la propia glosa confirman grosso modo esta data, pero permiten afinar algo más, incluso en lo referente a la fecha de redacción. De este modo, en la nota a la copla 78 hay alusiones a Juan II de Aragón (1458-1479) y Ferrante de Nápoles (1458-1494) como monarcas reinantes. Además, en la glosa a 97a, se refiere un prodigioso fenómeno atmosférico -probablemente un tornado- acontecido en Sevilla el 18 de febrero de 1464, hecho documentado por otros autores con la misma cronología -así, Alfonso de Palencia en sus Gesta Hispaniensia $(\mathrm{I}, 6,9)^{22}$-. Con estos elementos, podemos fijar la composición de esta glosa entre 1464 y 1479 .

Con respecto a su anónimo autor, del sobresaliente caudal de citas patrísticas, de literatura moral mediolatina y canonística de que hace alarde, cabe deducir que fue eclesiástico de sólida formación.

La sección dedicada al Laberinto en MM1 se abre con un epígrafe a modo de incipit: "[C]omiença otro tratado del dicho Juan de Mena llamado Las trezientas, porque ay en él trezientas coplas, o llamado Laberinto, que quiere dezir tanto como "trabajo de dentro", a semejança del laberinto". En cuanto rúbrica cancioneril, la formulación aporta elementos esperables, como el nombre del autor y, pues consta de tal, el título de la obra. Sin embargo, las explicaciones de la doble titulación -en particular, el comentario etimológico del término laberinto- se inscriben más bien en la tradición del accessus ${ }^{23}$.

20. Una descripción detallada de estos manuscritos y su contenido puede verse en la edición del Laberinto por Kerkhof, op. cit., p. 33-59. Sobre las glosas de PN7 y MM1, véase Julian Weiss, «El comentarista en su "Laberinto": Hernán Núñez y su edición de Juan de Mena», en A. Vilanova, Actas del X Congreso de la AIH, Barcelona, PPU, 1992, t. I, p. 571-577, y muy especialmente Maximiliaan Kerkhof, «Las glosas del Laberinto de Fortuna en los mss. PN7 y PMM1 (olim MM1)", en C. Moya, Juan de Mena: de letrado a poeta, Woodbridge, Tamesis, 2015, p. 217-253.

21. Véase PhiloBiblon (manid 3305), no 4 (2016). [En línea]. [Página consultada el 19 de julio de 2016]. bancroft.berkeley.edu/philobiblon.

22. Alfonso de Palencia, Gesta Hispaniensia ex annalibvs svorum diervm collecta, ed. de B. Tate y J. Lawrance, Madrid, Real Academia de la Historia, 1998-1999, t. II, p. 250-251.

23. Sobre la concepción de la rúbrica de cancionero, véase Cleofé Tato, «Las rúbricas en la poesía cancioneril», Patrizia Botta, «Las rúbricas en los cancioneros de Encina y de Resende», y Aviva Garribba, «Las rúbricas en los pliegos de romances del s. XVI», trabajos integrados en 
Acto seguido, la glosa introductoria confirma este extremo: se desarrolla la explanación del segundo título a través de Isidoro (Etimologías XV, 2, 36), con el texto latino y su romanceamiento, a propósito del laberinto del Minotauro, edificio trabajoso y complejo como el poema de Mena. Y si hasta este punto el comentario no dejaba de ser pertinente, de inmediato se aventura por la senda de la erudición farragosa y prescindible, cuando el anónimo glosador ilustra a sus lectores con la localización de los cuatro laberintos del mundo, de nuevo a partir de las Etimologías ${ }^{24}$.

Entre los constituyentes del accessus, por tanto, el título de la obra es el más interesante para el glosador de MM1, pues el étimo de laberinto le permite desplegar sus saberes filológicos. Sin embargo, esta parte de la glosa, al tiempo que aclara la titulación del poema, también se concibe para que, desde la explicación de laberinto, «los leyentes ignorantes [...] vengan en más conocimiento de la intención del actor», es decir, la vieja intentio auctoris, otro elemento del accessus. Pese a esta referencia expresa, de entrada el comentarista no declara nítidamente su concepto de la intención meniana; si acaso, esta queda subsumida en la analogía entre el laberinto y el poema: «Et assí como [el laberinto] es hedificio de paredes perplexas, así este tratado es comento o escriptura de materias grandes e difíciles». Pero después, cerrado el examen del título («Esto sea quanto al nombre del tratado»), la noticia de la dedicatoria del poema a Juan II permite entrever otra dimensión de la intentio auctoris a ojos del glosador: el rey es destinatario del poema

así porque en su tiempo fizo [Mena] la dicha obra como porque algunos cavalleros nobles generosos fenescieron sus vidas en actos strenuos de gloriosa milicia, dimicando con los infieles por la sancta fe cathólica, <de> los quales mílites en algún lugar el actor mencionará.

De este modo, se propone el elogio del sacrificio caballeresco en defensa de la fe como móvil poético de Juan de Mena.

No parece que este accessus del Cancionero de Barrantes haya llegado de primera mano a Núnez, ni mucho menos al Brocense. Los paralelismos se explican por poligénesis: las propias características del género y las fuentes comunes propician las coincidencias, por otra parte ligeras.

Tras el precedente de las glosas cuatrocentistas anónimas -sumemos el generoso uso de los versos de Mena como ilustración en la Gramática castellana y autoridad en la primera versión del Vocabulario español-latino de Nebrija-, la imprenta y la relevancia del erudito convierten el trabajo de Hernán Núnez,

la sección «Rúbricas» de Canzonieri iberici, ed. de P. Botta, C. Parrilla e I. Pérez Pascual, Noia, Toxosoutos-Università di Padova-Universidade da Coruña, 2001, t. II, p. 349-399.

24. La cita desmesurada - desde las Etimologías o el De imagine mundi, en particular- y la erudición impertinente son características de este glosador. Entre sus comentos más fastidiosos destaca la nota a propósito del v. 708 del Laberinto: aquí, el simple uso de la voz fe por Mena («non te membrando de fe nin d'amor») da pie a una vacua y amplia cita de Isidoro (Sententiae II, 2, 1-3, 6-8, 10 y 13-14), sobre el concepto teológico, que no viene al caso (MM1, fol. 53r, col. a). 
quien se considera pionero, en el primer gran hito del estudio del Laberinto de Fortuna. En 1499, a su regreso de Bolonia, un joven Pinciano da a la estampa su primera obra, una edición del Laberinto profusamente anotada. Para el Comendador Griego, Mena es el poeta castellano por excelencia y el Laberinto una obra apropiadísima -y no solo en el ámbito de las letras romances- para demostrar la validez de su método filológico. Con una segunda versión de 1505, tenemos constancia de quince ediciones del comentario de Núñez entre 1499 y $1566^{25}$.

En los preliminares de la redacción primitiva de esta glosa, Núñez dedica un apartado al accessus a Juan de Mena y el Laberinto, bajo el epígrafe «De la vida del auctor, y de la intinción que le movió a escrevir, y del título de la obra». Por añadidura, en el parágrafo introductorio se acoge también de modo expreso a aquella tradición filológica:

Porque veo ser costumbre usada entre los que exponen alguna obra, primero que vengan a la declaración d'ella, tratar de la vida del auctor y de la intinción que le movió a escrevir y de[l] título de la obra, seguiremos nosotros aquí esta orden, y de cada una d'estas cosas diremos algo antes que comencemos la exposición.

La aproximación de Núñez es, en realidad, más completa, porque a vida, intención y título se suma en su exposición un cuarto elemento, los «caracteres o formas de dezir", dentro del modus dicendi o forma del poema. En el incunable de 1499, estos cuatro constituyentes del accessus son puestos de relieve por breves escolios marginales a manera de titulillos y marcas mnemotécnicas.

En este conjunto, la subsección más detallada es la vida de Mena, que hoy se considera como la más completa y fiable fuente biográfica del poeta cordobés, con atención a su familia, su formación -durante un tiempo en Roma, «según dizen»-, sus tres poemas mayores -la Coronación, el Laberinto y las Coplas de los pecados mortales-, así como sus oficios funcionariales como veinticuatro de

25. De la versión de 1505 hay edición electrónica de Julian Weiss y Antonio Cortijo: Hernán Núńez, Las Trezientas del famosísimo poeta Juan de Mena con glosa. [En línea]. eHumanista [Página consultada el 19 de julio de 2016]. http://www.ehumanista.ucsb.edu/publications/trescientas. Sobre este comentario del Pinciano, véase Karl Kohut, «Der Kommentar zu literarischen Texten als Quelle der Literaturtheorie im spanischen Humanismus. Die Kommentare zu Juan de Mena und Garcilaso de la Vega», en A. Buck y O. Herding, Der Kommentar in der Rennaisance, Bonn, Deutsche Forschungsgemeinschaft, 1975, p. 191-208 [193-198], Julian Weiss, «Political Commentary Hernán Núñez’s Glosa a las Trescientas», en A. Deyermond y J. Lawrance, Letters and Society in Fifteenth-Century Spain, Llangrannog, Dolphin Book, 1993, p. 205-216; Teresa Jiménez Calvente, "Los comentarios a las Trescientas de Juan de Mena», Revista de Filología Española, no 82, 2002, p. 21-44 [28-36]; Juan Casas Rigall, Humanismo, gramática y poesía. Juan de Mena y los auctores en el canon de Nebrija, Santiago de Compostela, Universidade, 2010, p. 113-114; Ángel Gómez Moreno, «La fortuna del Laberinto», en Moya, op. cit., p. 153-161; Antonio Cortijo, «El Comentario de Hernán Núñez de Toledo y las ediciones de Coci (Zaragoza)», Revista de lenguas y literaturas catalana, gallega y vasca, $\mathrm{n}^{\circ}$ 16, 2011, p. 237-246, $\mathrm{y}$ «El Comentario de Hernán Núñez de Toledo y las ediciones de Coci (Zaragoza) (II)», en Moya, op. cit., p. 175185; y Sila Gómez Álvarez, «Los procedimientos de dignificación en el Comentario de Hernán Núnez al Laberinto de Fortuna», en Moya, op. cit., p. 163-174. 
Córdoba y "secretario de latín» de Juan II, hasta su muerte y entierro a expensas del Marqués de Santillana ${ }^{26}$.

Con respecto a la intinción del autor, Núñez desdobla los móviles de Mena en dos estratos: por una parte, el deseo de notoriedad común a los literatos -para lo cual se apoya en la autoridad de Cicerón y Ovidio, con pasajes citados y traducidos-; por otra, el objetivo de elogiar a Juan II y «otros famosos cavalleros que murieron en su tiempo haziendo guerra a los moros y en otras loables conquistas», en la línea del glosador anónimo del Cancionero de Barrantes, que, sin embargo, el Comendador Griego no parece conocer.

En cuanto al título de la obra, en primer lugar cabe destacar que Núñez se apoya en una rúbrica cancioneril, la misma que él aprovecha en su edición, abreviadamente citada aquí: "Comiença el Labyrintho de Juan de Mena, poeta castellano, intitulado al muy esclarecido y poderoso príncipe don Juan el segundo, rey de Castilla y de León, etc.». Sigue la esperable explanación etimológica de labyrintho y la glosa de su justa apropiación por Mena, pues su obra, como un laberinto, es igualmente «obscura y contiene muchos lugares difíciles de entender que no son obvios ni abiertos a todos». Por probable poligénesis, estamos otra vez en la línea del Cancionero de Barrantes, si bien los apuntes de Núñez son más sobrios y pertinentes ${ }^{27}$. Para clausura del párrafo, más novedosa resulta la relación de otros «títulos sobervios y arrogantes» análogos a Laberinto, como Enchiridion, Pandectas o Diatribas, a partir de Plinio, quien irónicamente los equiparaba a beber una imposible «leche de gallina».

El subapartado final del accessus se dedica a los «caracteres o formas de dezir». Que el culto Núñez conocía bien el comentario de Virgilio por Servio lo sabemos incluso por las noticias de su biblioteca: el Comendador Griego anotó de su puño y letra un ejemplar de la edición veneciana de Lazaro de Soardis, de 1491, actualmente en los fondos de la Universidad Complutense; además, Núñez cita a Servio en algunas glosas marginales de otros libros que manejó, en donde más ocasionalmente se sirve también de la Vita Vergilii de Donato ${ }^{28}$. Y otra manifestación del aprovechamiento de Servio por Núñez la tenemos en este punto del accessus del Laberinto, porque, more serviano, las «formas de dezir» se conciben como modalidades de voz narrativa: las personas tercera

26. Cfr. Florence Street, «La vida de Juan de Mena», Bulletin Hispanique, nº 55, 1953, p. 149-173.

27. Es difícil determinar los manuscritos del Laberinto que Núnéz pudo haber consultado. Su texto de 1499 se basa en el impreso de Sevilla, 1496, revisado en 1505 con apoyo de la princeps de Salamanca, 1481; especialmente en esta segunda versión, Núñez aprovechó la tradición manuscrita, pero poco sabemos sobre el proceso y los códices concretos. Véase Florence Street, "Hernán Núnez and the Earliest Printed Editions of Mena’s El Laberinto de Fortuna», The Modern Language Review, no 61, 1966, p. 51-63, y Maximiliaan Kerkhof y Rob le Pair, «El Laberinto de Fortuna de Juan de Mena: las ediciones en relación con la tradición manuscrita", en A. Sotelo y M. C. Carbonell, Homenaje al profesor Antonio Vilanova, Barcelona, Universidad, 1989, t. I, p. 321-339 [328-334].

28. Juan Signes, Carmen Codoñer y Arantxa Domingo, Biblioteca y epistolario de Hernán Núnez de Guzmán (el Pinciano). Una aproximación al humanismo español del siglo XVI, Madrid, CSIC, 2001, p. 191, 464, 486 y 489. 
-«en que solamente habla el poeta, como Vergilio en las Geórgicas»- y primera -molde en que solo hablan los personajes, "y este se llama dramático»-, al lado de la combinación de ambas voces, «en que a las vezes habla el poeta, a las vezes las personas que introduze, el qual siguió Vergilio en la Eneida y otros poetas latinos, y Juan de Mena en esta obra». El «actus mixtus, ubi et poeta loquitur et alios inducit loquentes» de Servio en su comentario de la Eneida (op. cit., p. 4) es el obvio marco teórico, de extraordinaria difusión a partir de las Etimologías (VIII, 7, 11) de Isidoro $^{29}$.

En este sentido, Hernán Núñez es uno de esos autores tardíos que ponen de manifiesto cómo los viejos patrones del accessus continúan vigentes para los humanistas. Pero solo hasta cierto punto, porque la segunda versión de su Laberinto glosado depara una sorpresa, y el accessus primitivo desaparece de los preliminares por ser considerado innecesario:

Las otras cosas que antes puse primero que viniesse a la declaración de la obra, quiero dezir el título de la obra, la vida del auctor, la intinción que le movió a escrevir, que los griegos llaman prolegomena, dexé de las poner aquí adrede porque no me pareció aver mucha necessidad de ellas ${ }^{30}$.

Y es que, a la altura de 1505, para Núñez el lastre medieval del accessus ya pesa más que la autoridad de Servio ${ }^{31}$.

En la centuria siguiente, un gramático aún más insigne también se aplicaría al estudio de Mena: en 1582, unos años después de haberse ocupado de los versos de Garcilaso, Francisco Sánchez de las Brozas publica Las obras del famoso poeta Juan de Mena, cuya glosa se centra en el Laberinto y, en menor medida, la Coronación. El Brocense aprovecha abiertamente la glosa de Núñez, pero, más sobrio, opta por un comentario escolar con parca explanación de lengua, mitos y alusiones históricas, además de enmiendas textuales y declaración de modelos. La edición meniana del Brocense conocería una segunda estampa en 1586; en cambio, no parece haberse materializado el proyecto de una edición conjunta de Mena y Garcilaso ${ }^{32}$.

29. El pasaje de Isidoro sobre los characteres lo recoge expresamente el glosador de MM1 (fols. 57v-58r), en su comentario de la copla 123 del Laberinto. Con todo, dada la difusión de las obras de Servio e Isidoro, de nuevo es natural la poligénesis en las citas análogas del anónimo y Núñez.

30. Weiss y Cortijo, op. cit.

31. Si damos crédito al testimonio de Bernardino Daza en el prefacio de su traducción de los Emblemas de Alciato (1549), el purismo clasicista de su coterráneo Núnez se impondría hasta inducirlo a renegar de su Laberinto glosado, que lo alejó de "otros más altos exercicios»: «Aunque no pienso que será tanto mj aumento en las letras, ny ellos [los Emblemas de Alciato] tan sin arte traduçidos, que me acaeçerá lo que a nuestro vnico v́nico restituidor de la antigüedad (que tal nombre le damos en estos reynos) con aquellos sus doctíssimos comentarios sobre las Treçientas del de Mena, que, con no se poder mejorar, le oý dezir muchas vezes que diera vna gran cosa por poderlos todos quemar, de tal manera que no sonara más en ellos su nombre», Los emblemas de Alciato traducidos en rimas españolas, ed. de R. Zafra, Barcelona, Olañeta-Universitat de les Illes Balears, 2003, p. 12 (puntuación y acentuación mías).

32. La edición glosada del Brocense se recoge en Juan de Mena, Obra completa, ed. de A. 
En la producción de Sánchez, el De auctoribus interpretandis es un programa de su concepción del comentario literario, basado en el Ars poetica de Horacio y al margen del accessus tradicional. Sin embargo, en la práctica de sus prólogos, el viejo patrón pervive, aunque sea secundario ${ }^{33}$.

En particular, el elemento del accessus que más interesa al Brocense es la vita. Conocedor de la tradición de vidas de Virgilio, en el comentario del Mantuano se burla de sus frecuentes errores en materia histórica (II, p. 196). Pero, bien fundamentada, la vida del autor es instrumento útil en los preliminares de la edición, y él mismo la cultiva en sus comentarios de Persio (II, p. 272) y Pomponio Mela -aquí a propósito del antropónimo (II, p. 520-521)-, tanto en latín como en romance -el caso de su Epicteto (III, p. 508)-, e igual en referencia a antiqui que a moderni -así, la vida de Andrea Alciato (III, p. 3-4)-.

En menor medida, Sánchez se ocupa de los títulos si entrañan algún problema. Así, por ejemplo, desconfía de las titulaciones otorgadas a las églogas de Virgilio (II, p. 178), o considera pertinente la explanación de un título figurado como el Gryphus de Ausonio (II, p. 256). Fuera de esto, domina su interés etimológico por la etiqueta de género en el título de la obra -de este modo, ecloga (II, p. 178), silva (II, p. 407) o emblema (III, p. 4-5)-.

Con estos fundamentos teóricos, en los prólogos de sus ediciones comentadas de Garcilaso (1574) y Mena (1582) se advierte una misma concepción como punto de partida, cuyo desarrollo, sin embargo, discurre por vías autónomas: ambos prefacios se dirigen "Al letor» para justificar el interés de las respectivas anotaciones, pero con distintos argumentos impuestos por cada circunstancia. En el caso de Garcilaso, el Brocense defiende la pertinencia de la declaración de fuentes, en consonancia con la legítima imitatio que ha guiado al autor: dado que no se puede tener "por buen poeta al que no imita los excelentes antiguos", que el glosador desvele sus modelos no es afrentar, sino honrar al autor (IV, p. 36-37). En la edición de Mena, la justificación encara otro problema de recepción: las «antiguallas» de un poeta del s. XV a ojos de los nuevos lectores áureos. Aquí, el Brocense se vale de dos razonamientos complementarios: Mena y su Laberinto no deben ser postergados a causa de la nueva estética literaria, al igual que, en Roma, Ennio o Lucrecio no cayeron en olvido con el advenimiento de Virgilio u Horacio; pero el Laberinto, además de su valor

Gómez Moreno y T. Jiménez Calvente, Madrid, Turner, col. «Biblioteca Castro», 1994. Sobre este comentario de Sánchez, véase Kohut, op. cit., p. 201-208, Jiménez Calvente, op. cit., p. 3742, Bienvenido Morros, «El Brocense en los textos de Juan de Mena y de Garcilaso de la Vega», en C. Codoñer, S. López Moreda y J. Ureña, El Brocense y las humanidades en el siglo XVI, Salamanca, Ediciones Universidad de Salamanca, 2003, p. 347-371; Casas Rigall, op. cit., p. 110-114, y Gómez Moreno, op. cit.

33. Manejo la edición de las obras completas del Brocense preparada por Mayans y Siscar: Francisci Sanctii Brocensis [...] Opera omnia, una cum ejusdem scriptoris vita, auctore Gregorio Maiansio [...], Ginebra, Fratres de Tournes, 1766, 4 vols. (reimpresión, Hildesheim-Zurich-New York, Georg Olms, 1985). El De auctoribus interpretandis se recoge en el tomo II, p. 73-96; las remisiones a otras obras del Brocense siguen estas Opera omnia. Sobre las conceptos poéticos en De auctoribus y su evolución en el Brocense, véase Luis Merino Jérez, La pedagogía en la retórica del Brocense, Cáceres, Universidad-Institución Cultural «El Brocense», 1992, p. 254-314. 
intrínseco, presenta otro mérito indudable en la perspectiva humanística: el elemento didáctico-moral.

Por ceñirnos al metalenguaje del accessus, en el prólogo brocensiano del Garcilaso domina el interés por la facultas, las fuentes del autor, mientras que en el correlato sobre Mena se hace hincapié en la utilitas, poética y ética. Pero, en ambos dominios, el viejo patrón del accessus se presenta muy desdibujado: la teoría de la imitatio, en el primer caso, y la vocación docente del Humanismo, en el segundo, son el fundamento inmediato. Con todo, hacia el final del prefacio de su edición de Mena, Sánchez recupera un constituyente obvio del accessus, la vida del autor, aunque solo sea para reconocer su escaso conocimiento:

En lo que toca a su vida, no sé por agora dezir más de que avrá más de ciento y sesenta años que floreció, porque el rey don Juan el segundo, a quien él celebra, començó a reinar año de 1407. Está sepultado Juan de Mena en Tordelaguna, en el Monasterio de Sant Francisco, y tiene su epitafio en la sepultura delante del altar de la Madalena:

\section{Patria feliz, dicha buena, \\ Escondrijo de la muerte, \\ Pues que te cupo por suerte \\ El poeta Juan de Mena.}

Antes que despreciar la vita de Mena según Hernán Núñez, Sánchez actúa condicionado por la segunda redacción del Pinciano, que, según hemos visto, omitía el accessus de 1499 y, así, la biografía del poeta. Lo curioso es que el Brocense, en la fase de preparación de sus anotaciones, fue advertido de su error y, aunque se comprometió a subsanarlo, no lo hizo. En carta a Juan Vázquez del Mármol (Salamanca, 21 de septiembre de 1579), que ha recibido un borrador de su Laberinto glosado, Sánchez le solicita noticias sobre la biografía de Mena: «Si v. md. supiese algo de la vida de Juan de Mena, suplico me lo avise. Yo tengo memoria dónde está enterrado, y no la hallo presente, y así va el prólogo en blanco» ${ }^{34}$. Finalmente el Brocense logró incorporar algunos detalles sobre el lugar del sepuclro y su epitafio. No obstante, Vázquez del Mármol le hizo ver su olvido de la vita de Mena en la primera edición del Comendador Griego, lapsus que Sánchez hubo de reconocer con sonrojo en otra epístola (Salamanca, 20 de mayo de 1580): «No sé (como v. md. dice) qué pudo ser la causa por que en estas nuevas falté. Yo determino de ponerla como allí está si a v. md. ansí le parece» $^{35}$. El caso es que nunca llegó a hacerlo.

34. Edita la epístola Bartolomé José Gallardo, Ensayo de una biblioteca española de libros raros y curiosos, formados con los apuntamientos de..., coordinados y aumentados por D. R. Zarco del Valle y D. J. Sancho Rayón, Madrid, Rivadeneyra-Tello, 1863-1889, t. IV, p. 453 (reimpresión, Madrid, Gredos, 1968); son míos los ligeros ajustes ortográficos y de puntuación. Aunque no comenta las cuestiones que estamos analizando, sobre la correspondencia entre el Brocense y Vázquez véase Isidoro Arén Janeiro, "Cartas a Juan de Vázquez del Mármol: el Brocense y las Anotaciones al Laberinto de Fortuna». [En línea]. Lemir, n o 15, 2011, p. 245-258. [Página consultada el 19 de julio de 2016]. http://parnaseo.uv.es/Lemir/Revista/Revista15/12_Janeiro_Isidoro.pdf.

35. El texto en Gallardo, op. cit., p. 453-454. 
Paradójicamente, la alegación de ignorancia de Sánchez con respecto a la vida de Mena demuestra el peso de la vieja tradición del accessus, que, aun a falta de noticias, se resiste a desaparecer por completo. No obstante, después de haber sido reconvenido, la incuria del Brocense pone de relieve cómo los antiguos patrones del comentario ya no son preocupación primordial del Humanismo.

En definitiva, el comentarista que más claramente y mejor se pliega a la estructura del accessus es Hernán Núnez en la primera versión de su Laberinto con glosas (1499), si bien en la redacción de 1505 decide omitir estos prolegómenos por considerarlos innecesarios, cuando la autoridad de la tradición serviana tiene ya menor peso que el interés por desmarcarse de un uso medievalizante. El glosador anónimo del Cancionero de Barrantes anuncia elementos del accessus en una rúbrica que declara con brevedad los títulos Las trezientas y, en particular, Laberinto, a continuación detallado etimológica e históricamente, un desarrollo típico del accessus; pero esta misma raíz se advierte incluso en la simple referencia a la «intención del actor», aun subsumida en la explicación del título del poema. Por lo que respecta a las anotaciones del Brocense, en otros de sus comentarios perviven trazas de elementos aislados del accessus, en especial la vita auctoris, que en la edición de Mena se reconstruye muy parcialmente, con escasas noticias en el marco de una incomprensible alegación general de ignorancia; en cambio, la atención a la utilitas del Laberinto, aunque materia típica del accessus, debe de tener en Sánchez otro origen, vinculado con los intereses éticos del Humanismo.

$\mathrm{Si}$ examinamos los componentes tradicionales del accessus en los tres comentaristas, el título del poema, tratado por el anónimo del Cancionero de Barrantes y Núnez, es el elemento más atendido, seguido por la vida de Mena -gracias a Núnez, con una pequeña aportación del Brocense- y su intención -de nuevo en Núnez, y, como cuestión sugerida más que detallada, en la glosa de MM1-. De la voz narrativa, célula del modus dicendi, se ocupa tan solo Núnez, y la utilitas de la obra se pondera en el prólogo del Brocense con otra raíz primordial.

Entre mediados del Cuatrocientos y 1584, la tradición del accessus en los comentarios del Laberinto no muestra una evolución paulatinamente regresiva, pues la glosa de Núñez en 1499, de cronología medial, manifiesta la mayor vigencia de la tradición. De forma sorprendente, es el mismo Núnez, en la segunda versión de sus comentarios, quien renuncia de modo expreso a cualquier modelo de accessus, prueba de que a comienzos del s. XVI los viejos patrones, aún vigentes, comienzan a ser discutidos. Todavía a finales de esta centuria perviven algunos elementos del accessus, pero cada vez más difusos en los nuevo prólogos del Brocense. 


\title{
II. TEXTOS ${ }^{36}$
}

\section{Accessus anónimo del Cancionero de Barrantes (MM1) (1464-1479) ${ }^{37}$}

\author{
(fol. 39r)
}

[C]omiença otro tratado del dicho Juan de Mena llamado Las trezientas, porque ay en él trezientas coplas, o llamado Laberinto, que quiere dezir tanto como 'trabajo de dentro', a semejança del laberinto.

E porque los leyentes ignorantes sean más introduzidos de la noticia d'este vocablo e por él vengan en más conoscimiento de la intención del actor e declaración del tractado, deven saber qué dize sant Isidro, arçobispo de Sevilla e doctor de las Españas, en el libro llamado De las ethimologías, fablando de los hedificios e cosas maravillosas de por el mundo. Dize así: «Laberintus est perplexis parietibus hedificium qualis est apud Alidedalo ${ }^{38}$, factus qualis fuit et ubi Minotaurus inclusus, in quo, si quis introierit, sine glomere lini exitum invenire non valet. Cuius hedificii talis est situs ut aperientibus foras tonitruum intus terribile audiatur; descenditur centenis ultra gradibus; intus simulacra et monstrifice effigies; in partes diversas transitus in errorem per tenebras et cetera ad errorem ingredientibus, ita ut de tenebris eius ad lucem venire imposibile videaturs [Etimologías XV, 2, 36]. Quiere dezir en vulgar que «laberinto es un hedeficio de paredes perplexas que está cerca de Alidedalo, fecho adonde el Minotauro se

36. Con respecto a la ortografía, unificamos algunos usos fluctuantes sin repercusión fonológica: se reserva $\langle\mathrm{u}\rangle$ e $<\mathrm{i}>$ para articulaciones vocálicas, $\langle\mathrm{j}\rangle \mathrm{y}\langle\mathrm{v}\rangle$ para articulaciones consonánticas, <ce i> para el fonema africado sordo y siempre <mb, mp $>$; análogamente, se reducen las consonantes reduplicadas expletivas, por lo general cultismos grafemáticos (así, el romance effigies>efigies). Las abreviaturas se desarrollan sin indicación. En su caso, las letras sobrantes se encierran entre paréntesis angulares y las omitidas se añaden entre corchetes, que también se emplean para precisar la localización de las fuentes declaradas por el autor; a pie de página se consignan las escasas enmiendas de otra clase. Los escolios marginales, breves marcas capitulares o mnemotécnicas, van entre llaves. Las contracciones del tipo desto se deshacen con apóstrofo (d'esto). Mayúsculas, separación de palabras, puntuación y acentuación siguen el uso moderno, al igual que la letra cursiva (en títulos, usos metalingüísticos y convenciones de cita).

37. Edito el pasaje correspondiente de MM1, el manuscrito B80-B-17 (olim 20-5-6) de la Biblioteca de la Fundación Bartolomé March (Palma de Mallorca). Para la historia textual del Cancionero de Barrantes, véase Brian Dutton y Charles Faulhaber, «The "Lost” Barrantes Cancionero of Fifteenth-Century Spanish Poetry», en J. S. Geary, Florilegium Hispanicum, Madison, HSMS, 1983, p. 179-202; y Juan Carlos Conde y Víctor Infantes, «Un nuevo fragmento del Cancionero de Barrantes", Revista de Literatura Medieval, $\mathrm{n}^{\circ}$ 11, 1999, p. 209-215. Para la descripción del fragmento MM1, véase Ma Jesús Díez Garretas, «Descripción codicológica de MM1. Cancionero de Barrantes, Biblioteca de la Fundación Bartolomé March Servera, ms. B80-B-17». [En línea]. Cancioneros impresos y manuscritos. Descripciones codicológicas, 2013 [Página consultada el 19 de julio de 2016]. http://www.cancioneros.org/adjuntos/MM1.pdf.

38. El extrańo topónimo Alidedalo es deturpación de a Dedalo, el mítico constructor del laberinto de Creta. La noticia correcta la había tomado Isidoro de Servio (In Vergilii Aeneidos, $5,588)$. 
encerró, en el qual, si alguno entrase sin montón de cuerda o de ovillo de filo o cuerda, la salida non podrá fallar. Cuyo fito del tal hedificio es tal que <a> los que están cerca d'él por defuera oyen grand tronido e espantable, e descienden a él por cient gradas o escalones, e más de dentro ay muchos simulacros e monstruosas cosas e efigies; por diversas partes d'él el paso suyo es en error por teniebras, así que de sus teniebras a luz venir imposible será».

Semejante es este tratado a este laberinto, lo uno porque ay dentro en él mucho trabajo, según el vulgar romance d'este vocablo, que laberinto o laborinto, que es todo una cosa, todo quiere dezir una significación, que es labor intus «trabajo de dentro»" ${ }^{39}$. Et así como es hedificio de paredes perplexas, así este tratado es comento o escriptura de materias grandes e difíciles. En el qual tratado o scriptura el que entrare o leyere le conviene que lieve para lo entender ovillo de cuerda asaz luenga, que es ayuntamiento de saber muchas e diversas facultades, así istorial como de pohesía e otras sciencias que continuamente toca.

\{Laberinto\} Dexadas de vulgarizar las otras cosas de la difinición de laberinto, por quanto bastó esta primera parte por su propósito, brevemente fablaré quántos son estos laberintos, e digo que son quatro en todo el mundo e non se fallan más. El primero es en Egipto. \{En este se e[ncerró] el Minot[auro] $\}^{40}$ El segundo es en Creta, que agora se llama Candía e llamose Creta, que quiere dezir tanto como crieta, por "abertura», porque allí es una abertura e cueva de aquellas quatro; e esta tierra de Creta o Candía es agora del señorío de los venecianos, e es en el imperio de Grecia e llamose antiguamente Centápolis, que quiere dezir "cient cibdades», las quales avía allí todas pobladas en aquella isla de Creta o de Candía. Así lo menciona el sobredicho señor sant Isidro en el libro «De propietatibus rerum» [Etimologías XIV, 6, 15], fablando de las islas. Et aun este auctor, fablando de las islas: el tercer laberinto es en Lenon et el quarto en Italia, et dize d'ellos sant Isidro: "Quod omnes sic sunt constructi ut dissolvere eos nec seccula quidem possunt» [Etimologías XV, 2, 36]; quiere dezir que «así están todos fechos que todos los siglos non los podrán desfazer».

Esto sea quanto al nombre del tratado. Otrosí el actor dirige su obra al sereníssimo e ilustríssimo señor rey de Castilla e de León don Juan el segundo, así porque en su tiempo fizo la dicha obra como porque algunos cavalleros nobles generosos fenescieron sus vidas en actos strenuos de gloriosa milicia, dimicando con los infieles por la sancta fe cathólica, <de> los quales mílites en algún lugar el actor mencionará.

39. Como ha advertido Kerkhof, op. cit., p. 239-240, esta pseudoetimología figura en los principales vocabulistas medievales, a saber, Papias, Uguccione da Pisa y Johannes Balbi.

40. Escolio parcialmente guillotinado en el margen derecho: en la reconstrucción hipotética, el nombre Minotauro es obvio; para el lugar previo, me baso en el propio texto supra: «[...] adonde el Minotauro se encerró [...]». 


\section{Hernán Núnez, Las .ccc. del famosíssimo poeta Juan de Mena con glosa $(1499)^{41}$}

$($ fol. iv $)[\ldots]$

De la vida del auctor, y de la intinción que le movió a escrevir, y del título de la obra.

Porque veo ser costumbre usada entre los que exponen alguna obra, primero que vengan a la declaración d'ella, tratar de la vida del auctor y de la intinción que le movió a escrevir y de[l] título de la obra, seguiremos nosotros aquí esta orden, y de cada una d'estas cosas diremos algo antes que comencemos la exposición.

\{La vida del auctor\} Y quanto a la vida del poeta, Juan de Mena fue natural de Córdova, cibdad principal en el Andaluzía, hijo de un ciudadano de ella llamado, segund algunos dizen, Pedrarias \{Pedrarias\}, hombre de mediano estado, y de una hermana de Rui Fernández de Peñalosa ${ }^{42}\{$ Rui Fernández de Peñalosa\}, veinte y quatro en la dicha ciudad y señor de Almenara. Y como pocos días después de Juan de Mena nascido su padre fallesciesse, quedaron él y una hermana suya huérfanos; y passada Juan de Mena su niñez entre sus parientes, siendo de edad de veinte y tres años, començó a dar obra al estudio de las letras: aprendió en Salamanca y en Córdova, y, según dizen, fue a Roma \{Roma\} y allá también aprendió algund tiempo. Casó en Córdova con una hermana de García de Vaca y Lope de Vaca \{García de Vaca y Lope de Vaca\}; no ovo hijos. Fue muy dado al estudio de la oratoria y poesía y a la composición del metro castellano, en el qual fue tan excelente que entre todos los otros poetas castellanos obtuvo tanta ventaja "velut inter ignes / luna minores", como dize Horacio [Carmina I, 12, 47-48]. Y ni antes d'él ni hasta nuestros tiempos ni en los venideros, si es de dezir, pienso que avrá otro con quien le podamos comparar. \{Tres obras principales de Juan de Mena\} Compuso, entre otras obras, tres principales: la primera, la Coronación del preclaríssimo y literatíssimo cavallero el señor don Ínígo López de Mendoza, marqués de Santillana, ahuelo de vuestra magnificentíssima señoría ${ }^{43}$; la segunda, estas Trezientas, en las quales con el fervor de la juventud se demostró muy imitador de los poetas antiguos; la tercera y última, más llegada a la contemplación y a nuestra religión, fue las Coplas de los vicios y virtudes, la qual, prevenido de la muerte, no pudo acabar. \{Juan de Mena, secretario de latín del rey don Juan. Juan de Mena, veinte y quatro de Córdova y boz mayor\} Fue secretario de latín del rey don Juan y veinte y quatro de Córdova, el qual oficio administró con

41. Hernán Núńez, Las .ccc. del famosíssimo poeta Juan de Mena con glosa, Sevilla, Juan Pegnitzer, Magno Herbst y Tomás Glockner, 1499. Ejemplar de la Biblioteca Nacional de España, Inc. 1512. Aunque la edición de Weiss y Cortijo, op. cit., se basa en la versión de 1505, incluye también este accessus de 1499, con omisión de sus escolios marginales.

42. Peńalosa] Peńaloza 1499.

43. Pues el destinatario de la obra de Núñez es Î́nigo López de Mendoza, Conde de Tendilla y nieto del Marqués de Santillana. 
tanta prudencia que fue boz mayor en el cabildo; y después, quando intituló esta obra al rey don Juan, el Rey le hizo su coronista. \{La muerte de Juan de Mena. Tordelaguna\} Murió, segund veo ser común opinión, de dolor de costado, siendo de edad de quarenta y cinco años. Está enterrado en la iglesia de Tordelaguna, lugar del arçobispado de Toledo, cabe el altar mayor, donde le mandó enterrar el sobredicho (fol. vr) Marqués de Santillana, ahuelo de vuestra ínclita señoría, el qual le mandó fazer la sepultura a sus espensas. Y esto quanto a la vida de Juan de Mena.

\{De la intinción que movió a escrevir a Juan de Mena\} Quanto a la intinción que le movió a escrevir, fue la que por la mayor parte suele mover a todos los que escriven algunas obras: desseo de ser loados y tenidos por scientes, y hazer su nombre inmortal, porque, como Tulio $\{$ Tulio\} escrive en la primera Thusculana [I, 4], «honos alit artes omnesque incendimur ad studia gloria», que quiere dezir "la honra en las artes y todos nos incitamos al estudio por cobdicia de la gloria» $\{$ La honra en las artes nota\}. No ignoró esto Ovidio \{Ovidio\} quando dixo en el tercero De arte amandi [III, 403-404]: "Quid petitur sacris, nisi tantum fama, poetis? / Hoc votum nostri summa laboris habet»; significa "¿Qué piden los sacros poetas sino sola la fama? Este es el último fin de nuestro trabajo». Otrosí movió a Juan de Mena gana de escrevir los hechos del rey don Juan, en cuyo tiempo él floreció, y de otros muchos famosos cavalleros que murieron en su tiempo haziendo guerra a los moros y en otras loables conquistas.

\{Del título de la obra\} Quanto al título de la obra, es este: «Comiença el Labyrintho de Juan de Mena, poeta castellano, intitulado al muy esclarecido y poderoso príncipe don Juan el segundo, rey de Castilla y de León, etc.». \{Labyrintho\} Donde es a saber que labyrintho era antiguamente edificio en parte debaxo de tierra, lleno de muchas callejas y puertas, y salidas y entradas, tan semejantes las unas a las otras que quien allí entrava era impossible poder salir si no llevasse alguna guía que toviesse muy decorados y sabidos los flexuosos ámbitos de aquel edificio. Y a semejança de este edificio que contenía en sí mucha dificultad para poder salir d'él el que una vez entrasse, llama Juan de Mena a esta su obra Labyrintho, porque es obscura y contiene muchos lugares difíciles de entender que no son obvios ni abiertos a todos. Y en esta foelicidad de título imitó Juan de Mena a algunos auctores que, por el semejante, pusieron a sus obras títulos insolentes y superbos \{Titulos sobervios y arrogantes\}, como digamos, Ceras amaltheas, Copie cornu, Musarum silvarum, Lectionum antiquarum, Lectiones sue, Pinacidion, Enchiridion, Pandectas, Diatribas, De regia philosophia, De natura humana, Epistolicarum questionum, Memoriales titulos, Limon, y otros títulos festivos y amoenos con los quales pensaras que has de hallar en el libro «leche de gallina», como dize Plinio [Naturalis historia, "Praefatio», 24] \{Plinio\}.

\{Tres caracteres o formas de dezir\} Item es de notar que los poetas de qualquier género que sea escriven en uno de tres caracteres o formas de dezir. El primero es en que solamente habla el poeta, como Vergilio en las Geórgicas. El segundo es en que nunca habla el auctor, sino las personas que introduze, y este se llama dramático \{Dramático\}, del qual usan los poetas cómicos y trágicos. El 
tercero es mezclado de estos dos, en que a las vezes habla el poeta, a las vezes las personas que introduze, el qual siguió Vergilio en la Eneida y otros poetas latinos, y Juan de Mena en esta obra.

E porque los nuevos scriptores adqui[e]ren mayor auctoridad si confirman lo que dizen con testimonios de idóneos y aprovados auctores, y assimismo, como dize Plinio \{Plinio\}, es de hombres ingenuos y verecundos confessar por quién aprovechan [Naturalis historia, "Praefatio", 21], quise poner aquí los nombres de aquellos escriptores a quien sigo y de quien recoligí y tomé todo lo que en esta mi exposición puse. Los quales, entre philósophos, theólogos, oradores, poetas, gramáticos, mathemáticos, históricos y geógraphos, son passados de ciento y cincuenta $[\ldots]^{44}$.

\section{Francisco Sánchez de las Brozas, Las obras del famoso poeta Juan de Mena $(1582)^{45}$}

(fol. sign. ${ }^{*}{ }^{\mathrm{r}}$ )

El maestro Francisco Sánchez al lector, salutem.

Si, como dize Horacio, aquellos poetas deven ser preferidos que mezclaron dulçura con utilidad, non sé yo en nuestra lengua (y aun por ventura en las otras) quién con razón se pueda anteponer a nuestro Juan de Mena; porque la materia que trata es una philosophía moral y un dechado de la vida humana, ilustrada con diversos exemplos de historias antiguas y modernas, donde se halla doctrina, sabor y elegancia.

Dizen algunos que es poeta muy pesado y lleno de antiguallas, y di(fol. sign. ${ }^{*} 5^{v}$ ) zen esto con tanta gravedad que, si no les creemos, parece que les hazemos injuria; y no advierten que una poesía heroica como esta, para su gravedad, tiene necessidad de usar de palabras y sentencias graves y antiguas para levantar el estilo. Y, al fin, los que hallan este poeta por pesado son unos ingenios que ponen todo su estudio en hazer un soneto o canción de amores que para entenderlos es menester primero preguntarles a ellos si lo entendieron.

Es muy bien que este poeta sea tenido en mucha estima, aunque no fuera tan bueno como es, por ser el primero, que sepamos, que aya ilustrado la lengua castellana. Aunque en Roma salió Virgilio y Horacio y otros de aquel siglo, nunca Ennio y Lucrecio y (fol. sign. $\left[{ }^{*} 5^{2 \mathrm{r}}\right]$ ) los muy antiguos dexaron de ser tenidos en gran veneración. Ansí que no ay razón de desechar a Juan de Mena porque en nuestra edad ayan salidos otros de estilo muy diferente. Antes, este poeta ha de ser tenido en mucho porque le pueden leer todas edades y calidades de personas por ser casto y limpio y provechoso, donde las costumbres no

44. Sigue la lista de tales autoridades que, en cuatro columnas, ocupa el fol. vv.

45. Francisco Sánchez de las Brozas, Las obras del famoso poeta Juan de Mena nueuamente corregidas y declaradas por el maestro [...], Salamanca, Lucas de Junta, 1582. Ejemplar de la Biblioteca Nacional de España, signatura U/11436. La glosa íntegra del Brocense ha sido editada por Gómez Moreno y Jiménez Calvente, op. cit. 
recibirán mal resabio, lo qual no se puede assegurar de los otros poetas, a lo menos de algunos.

Yo espero que, leyéndose agora este poeta con más claridad y menos pesadumbre que antes, será mi trabajo bien recibido, principalmente de aquellos que están hartos o apartados de leer cosas lascivas y amorosas.

En lo que toca a su vida, no sé por agora dezir más de que avrá (fol. sign. $\left[{ }^{*} 5^{2 v}\right]$ ) más de ciento y sesenta años que floreció, porque el rey don Juan el segundo, a quien él celebra, començó a reinar año de 1407. Está sepultado Juan de Mena en Tordelaguna, en el Monasterio de Sant Francisco, y tiene su epitafio en la sepultura delante del altar de la Madalena:

Patria feliz, dicha buena,

Escondrijo de la muerte,

Pues que te cupo por suerte

El poeta Juan de Mena ${ }^{46}$.

46. El Brocense confunde el monasterio de San Francisco con la iglesia de Santa María Magdalena, ambos en Torrelaguna (olim Tordelaguna). Después de diversos traslados -incluidos una exhumación en 1869 con destino al fallido primer Panteón de Hombres Ilustres en Madrid, y su depósito en el Museo Arqueológico Nacional de 1936 a 1940-, los supuestos restos de Mena volvieron a la mencionada iglesia, aunque no a su primitivo emplazamiento. En el primer tomo de la Colección de poesias castellanas anteriores al siglo XV (Madrid, Sancha, 1779), Tomás Antonio Sánchez incluye una biografía del Marqués de Santillana en donde, a propósito de la muerte de Mena, da noticia de un epitafio en el templo «en la primera grada del presbyterio» (p. 22), con texto muy similar al testimonio del Brocense: «feliz patria dicha buena / escondrijo de la muerte / aqui le cupo por suerte / al poeta juan de mena» (ibid.). Sin embargo, esta lápida no representa ya el modelo primitivo: por entonces, Antonio Ponz declaraba en el Viage de España (Madrid, Ibarra, 1781, t. X, "Carta III", \$11) haber visto el epitafio en el mismo lugar, con la precisión de que la piedra original había sido renovada: «Estaban muy gastadas las letras y el Señor D. Pedro González, Obispo de Ávila [...], la hizo renovar no ha muchos años» -el episcopado de don Pedro, natural de Torrelaguna, abarcó de 1743 hasta su muerte en 1758-. Esta debe de ser la lápida conservada aún hoy, con una inscripción idéntica al texto de T. A. Sánchez. Ponz cita el epitafio con una ligera variante sintáctica (Patria feliz), coincidente con la lectura del Brocense, en un probable caso de poligénesis textual. 
